Entrevista - Diálogos Midiológicos 45

\title{
Influenciadores digitais, celebridades da internet e "blogueirinhas": uma entrevista com Crystal Abidin
}

Digital influencers, internet celebrities and "blogueirinhas": an interview with Crystal Abidin Influencers, celebridades de internet y "blogueirinhas": una entrevista con Crystal Abidin

DOI: https://doi.org/10.1590/1809-58442021114

\section{Crystal Abidin ${ }^{1}$}

https://orcid.org/0000-0002-5346-6977

\section{Entrevista concedida a:}

Issaaf Karhawi ${ }^{2}$

https://orcid.org/0000-0001-9907-0129

${ }^{1}$ (Curtin University, School of Media, Creative Arts and Social Inquiry, Faculty of Humanities. Perth - Austrália).

${ }^{2}$ (Universidade de São Paulo, Escola de Comunicações e Artes, Centro de Estudos Latino-Americanos sobre Cultura e Comunicação. São Paulo - SP, Brasil).

Crystal Abidin é antropóloga e reúne, em seu currículo, multidisciplinaridade e internacionalização da pesquisa. Doutora em Ciências Sociais pela University of Western Australia, Abidin também passou pelo Departamento de Sociologia da National

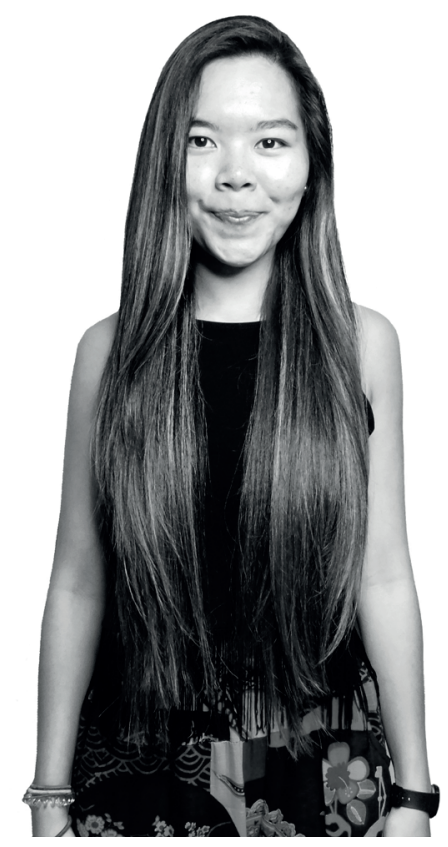
University of Singapore e pelo Media Management and Transformation Centre, da Jönköping University (Suécia). Suas pesquisas estão voltadas para culturas da internet e, especialmente, influenciadores digitais, celebridades, visibilidade online e cultura pop nas redes sociais digitais, com ênfase na região Ásia-Pacífico.

Atualmente, Crystal Abidin atua como docente e pesquisadora sênior na Curtin University (Austrália), como integrante do comitê executivo da Association of Internet Researchers (AoIR) e como membro do conselho editorial dos seguintes periódicos: Cultural Science Journal, Convergence, Journal of Communication, Journal of Sociotechnical Critique e Social Media + Society. Abidin também é autora do livro Instagram: Visual Social Media Cultures (Polity Press, 2020), em coautoria com Tama Leaver e Tim Highfield; Microcelebrity 
Around the Globe: Approaches to cultures of internet fame (Emerald Publishing, 2018), ao lado de Megan Lindsay Brown e Internet Celebrity: Understanding Fame Online (Emerald Publishing, 2018).

Nesta entrevista, realizada virtualmente no mês de agosto de 2020, Crystal Abidin apresenta resultados de quase dez anos de pesquisas sobre influenciadores digitais. As respostas vão contemplar desde definições mais basilares sobre as celebridades da internet e os influenciadores, questões de comercialidade, cultura de plataformas, influenciadores digitais minoritários e até a relação do mercado de influência digital e a pandemia de Covid-19.

\section{Revista Intercom - Crystal, para iniciar nossa conversa, a primeira pergunta será aparentemente simples: como você definiria o influenciador digital?}

Crystal Abidin - Para definir o influenciador digital, eu preciso dar um passo atrás e primeiro definir a celebridade da internet. Desse modo, é possível pensar em um framework interdisciplinar que, a priori, pode auxiliar na compreensão de quem são os influenciadores digitais mesmo em pesquisas contrastantes e em diferentes países. Primeiramente, a ideia de celebridade da internet se refere a um tipo de presença midiática com grande visibilidade online. E essa visibilidade pode ser atribuída a qualidades positivas ou negativas. Por exemplo, fama ou infâmia, atenção negativa ou positiva, presença ou ausência de talento, longo prazo ou curto prazo, intencional ou acidental, monetizado ou gratuito. Todos esses pares de qualidades podem se apresentar em diferentes combinações. O principal atributo das celebridades da internet seria o acúmulo de uma audiência que recebe certo tipo de informação, assiste, reconhece e contribui, de certo modo, oferecendo alta visibilidade para esses sujeitos midiáticos. Os influenciadores digitais, por sua vez, são um tipo de celebridade da internet para quem esses pares de qualidades costumam pender mais positivamente. Assim, entre fama e infâmia — como, por exemplo, entre boa reputação e escândalos — grande parte dos influenciadores cultiva sua fama por meio de reputação positiva, talentos e habilidades. Assim, eles buscam formas de sustentar essas qualidades por um longo período, cultivá-las, incrementá-las intencionalmente e monetizá-las. Influenciadores são, portanto, um tipo muito específico de celebridades da internet que buscam transformar essa visibilidade online em uma carreira digital remunerável. E, claro, se pensarmos nas operações dos influenciadores digitais, o que eles costumam fazer é usar as plataformas de redes sociais para divulgar revelações muito íntimas e novidades constantes de sua vida privada. E, como resultado, eles usam esse conteúdo para inserção de informes publicitários, anúncios e mensagens pagas. Essa definição é muito ampla, mas ela também permite considerar diferentes variedades de influenciadores. Assim, não trataremos apenas dos populares influenciadores de estilo de vida que falam sobre si nas redes, mas também poderemos incluir as celebridades dos memes - pessoas que são a cara de um meme - , ou crianças que podem ter se tornado virais da internet de forma acidental. Assim, esse framework mais abrangente permite a inclusão de suas diferenças. 
Revista Intercom - Há algumas perspectivas de pesquisa mais comuns no Brasil, quando se trata dos influenciadores digitais. Uma delas é baseada nos estudos de celebridades; e outra mais inclinada aos debates acerca do trabalho digital. Como você observa essas possibilidades de compreensão desse fenômeno?

Abidin - Quando falamos na Cultura de Celebridades, tendemos a focar mais em influenciadores considerados bem-sucedidos quanto à visibilidade. Mas há influenciadores que ocupam níveis muito baixos do espectro de visibilidade e, ainda assim, são considerados proeminentes em plataformas ou grupos muito específicos. Nesse caso, eles são microcelebridades para seus seguidores de nicho. Ainda assim, a sociedade e a mídia mainstream podem não os encarar como celebridades por conta desse nível de visibilidade. Portanto, o ponto chave aqui é em qual lugar do espectro de visibilidade um influenciador está, mais do que encará-lo nos termos da cultura de celebridades ou do trabalho digital. Isso porque, dependendo de quem é o público desse influenciador, sempre haverá algum tipo de valor de celebridade agregado a ele. Um exemplo são os TikTokers: ainda que eles sejam celebridades para a geração Z ou para crianças ainda mais jovens, para a audiência “comum” eles não passam de anônimos. Esse é um bom exemplo para mostrar como conceitos e aplicações que determinam quem é ou não uma celebridade, passam a ser fluidos e dependentes da audiência. Por sua vez, celebridades da internet e influenciadores digitais estão todos engajados em alguma forma de trabalho digital. Em certos casos, podemos tratar de trabalho intencional, por ocasião, de curto prazo, longo prazo, mas sempre veremos que os influenciadores mais proeminentes se dedicam a construção de uma carreira, investem mais na atividade e buscam um resultado bem-sucedido. Assim, eu não diria que se trata de duas perspectivas diferentes, mas dois pontos de vista: um que valoriza o viés da audiência, em quanta visibilidade se tem e, consequentemente, aproxima-se dos estudos de celebridades, cultura de celebridades. E o outro ponto está mais focado na perspectiva do influenciador e em quanto esforço é necessário para tornar-se um. Desse modo, mais preocupado com as noções de trabalho digital. Há, ainda, uma terceira perspectiva, que é a da ecologia da informação ou da comunicação. Nesse caso, são observadas as habilidades dos influenciadores digitais em amplificar ou suprimir alguns tipos específicos de informação, tensões, pensamentos e conversações. Em alguns casos, os influenciadores são capazes de angariar atenção e endossar mensagens que podem ser tanto de clientes, promovendo produtos de higiene e beleza, quanto promoção de mensagens sociais, de direitos humanos ou políticas. Em qualquer um desses exemplos, os influenciadores digitais desempenham um papel importante na ampliação da atenção para determinados assuntos. Na mesma medida, eles podem desempenhar um papel igualmente bom em desviar a atenção, distrair as pessoas e, portanto, suprimir alguns tópicos de conversas. Aqui, por fim, ao invés da perspectiva das audiências das celebridades, do criador de conteúdo e de seu trabalho, estamos olhando para a perspectiva da ecologia da informação e para os fluxos de comunicação e conteúdo envolvidos nesses processos. 
Revista Intercom - No artigo Communicative Intimacies: Influencers and Perceived Interconnectedness (ABIDIN, 2015), você discute algumas diferenças nas formas como os seguidores se relacionam com os influenciadores digitais e com as celebridades tradicionais. Seus achados de pesquisa revelam a existência de uma "percepção de intimidade” que torna a relação com os influenciadores percebida como mais íntima e próxima, diferente daquela estabelecida com as celebridades clássicas. Você poderia falar um pouco sobre isso?

Abidin - A principal diferença entre os influenciadores digitais (ou celebridades da internet) e as celebridades midiáticas tradicionais é a sua história de origem. Influenciadores eram considerados sujeitos que se fizeram a partir da base, “do povo”. Ou seja, eles estavam ali há anos com sua voz, autenticidade, informalidade, conteúdo orgânico e pensamentos autênticos. Influenciadores digitais eram usuários da internet comuns, como eu e você, que acabaram tendo um pouco mais de fama e visibilidade online. Portanto, eles têm muito mais proximidade e intimidade com pessoas comuns - com quem estão tentando se relacionar - quando comparados com celebridades tradicionais que são consideradas personagens de alto padrão, elitizadas e intocáveis. Por essa razão, muitas das mensagens que os influenciadores endereçam a suas audiências devem vir no formato de um "editorial personificado"; não basta que estejam agindo como modelos em um outdoor ou segurando produtos como embaixadores, a mensagem pessoal e a história pessoal de como algo funcionou para eles em suas vidas é uma grande parte de sua relacionalidade ${ }^{1}$. Isso porque os influenciadores digitais estão tentando nos lembrar que são muito parecidos conosco, com seus públicos. E, portanto, aquilo que funciona para eles, funcionará para qualquer um de nós. Como exemplo, eu sempre uso em minhas aulas o caso dos cremes para espinhas. Se a atriz Angelina Jolie disser que alguns cosméticos ou cremes para espinhas funcionam para ela, a mensagem pode não ser tão confiável para nós. Isso porque sabemos que ali há recursos, experiências e expertises que permitem um certo tipo de conhecimento e práticas de cuidados com a pele. É diferente quando uma pessoa compartilha com seus seguidores não apenas o seu eu sob holofotes, como o faz Angelina Jolie, mas também suas dificuldades com os cuidados da pele, bastidores, tentativas de sucesso e fracasso, produtos que funcionam e que não. Quando essa mesma pessoa finalmente retorna e conta que há um produto específico que funcionou para sua pele, é provável que os seguidores estejam mais inclinados a acreditarem em sua história, já que acompanharam todo o processo e as lutas por trás das câmeras até a solução encontrada. Quando essa pessoa, um influenciador digital, usa seu tempo online para compartilhar suas próprias vulnerabilidades, isso faz com que se instaure uma relação de equidade entre aqueles que o acompanham - um certo efeito de igualização. E, consequentemente, a mensagem é mais crível. Esse exemplo faria parte de

1 Originalmente, Abidin usa a palavra relatability que compreende o conceito de relacionalidade, ou seja, "condição humana de interagir com o outro, identificando-o como um semelhante; portanto diz respeito à alteridade e engloba necessariamente a empatia” (SILVA; ANJOS, 2018, p. 151). 
um framework ${ }^{2}$ mais amplo que referimos como relacionalidade [relatability]. Muito do que os influenciadores digitais fazem hoje é uma versão atualizada do que se compreende como relações parassociais (ou interações parassociais). Essa noção foi cunhada pelos psicólogos sociais Horton e Wohl (1956) e, à época, eles buscavam compreender como as audiências em casa - assistindo ao mesmo programa televisivo todos os dias ou escutando ao mesmo programa de rádio - podiam se sentir tão conectadas às celebridades, ainda que nunca as tivessem conhecido pessoalmente. Como resultado da investigação, os autores puderam desenhar um framework de relações parassociais com alguns elementos: que meios eram usados, quais eram as estratégias primárias, quem originou a estratégia, como os atores estavam organizados nessa relação. Cada um desses elementos é discutido no trabalho que você referencia na pergunta: Communicative Intimacies: Influencers and Perceived Interconnectedness. É possível fazer uma combinação desse cenário ao nosso espaço na era digital, dessa vez, olhando para celebridades e influenciadores. Atualmente, a mídia social permite que os influenciadores usem a intimidade como estratégia primária e há muitos tipos diferentes de intimidades: intimidades comerciais, interativas, recíprocas e reveladoras. A organização dos atores (agentes) é menos hierárquica e mais plana. A distribuição não é mais tanto broadcast e topdown, mas mais interativa - em que seguidores, fãs e até haters podem interferir. O fluxo da conversa também deixou de ser unidirecional e passou a ser bidirecional - há influenciadores que recebem respostas dos seguidores e as incorporam no conteúdo que produzem. Portanto, visto que este é um tempo diferente, em plataformas diferentes e tipos também diferentes de personalidades públicas, a intimidade que sentíamos com as celebridades tradicionais foi profundamente intensificada, refeita e atualizada pelos influenciadores digitais de hoje.

Revista Intercom - Em outro artigo, \#familygoals: Family Influencers, Calibrated Amateurism, and Justifying Young Digital Labor (ABIDIN, 2017), você discute como os influenciadores digitais usam uma percepção de amadorismo - ainda que sejam altamente profissionalizados - para se conectarem de forma mais efetiva com suas audiências. Parece que esse conceito se relaciona diretamente com o que você está apresentando aqui.

Abidin - Sem dúvida. Muitos influenciadores estão se tornando cada vez mais profissionalizados, alguns até envoltos em luxo e, certamente, tornando-se alguns dos sujeitos mais bem-sucedidos financeiramente do mundo - rivalizando, inclusive, com celebridades. Como resultado, nota-se uma tendência de afastamento entre influenciadores e suas audiências, uma vez que as pessoas não os veem mais como iguais e usuários orgânicos da rede. No começo, as pessoas realmente tinham um sentimento de proximidade, de relacionalidade, oriundo da força trazida pelo efeito de base dos influenciadores digitais, sua história de origem. Paralelamente, no entanto, também há uma mudança de clima nas

2 O framework mencionado pela pesquisadora foi traduzido no artigo "Na tela da TV e do computador: as celebridades youtubers" (KARHAWI, 2017b). 
redes sociais digitais. A chegada e a popularização do Instagram [Instagram Cultures], por exemplo, privilegiou essa apresentação da perfeição nas mídias sociais. Antes disso, embora houvesse outros aplicativos de compartilhamento de fotos e imagens, o prestígio e o luxo trazidos pelo Instagram ainda não integravam a cultura dominante. Assim, com essa combinação de influenciadores mais profissionalizados e a popularização das culturas do Instagram, mais os influenciadores estão se afastando de seus públicos. Então, com a intenção de restaurar essa ilusão de acessibilidade, de promover mais uma vez sentimentos de relacionalidade, muitos influenciadores gastam muito tempo para criar intencionalmente imagens de amadorismo e conferir uma estética que, supostamente, minimizaria seu status, sucesso e renda e, portanto, seria capaz de trazer as pessoas para mais perto novamente. E é possível ver isso acontecendo de diversas formas. No YouTube, por exemplo, influenciadores mostram o que acontece quando cometem erros, mostram bastidores de suas gravações, o passo-a-passo de suas maquiagens e preparação para eventos. Alguns influenciadores vão ao extremo em suas revelações confessionais, ao mostrar suas vulnerabilidades e mesmo colapsos emocionais. Há revelações sobre término de relacionamentos, incidentes vividos, às vezes até a articulação de controvérsias e escândalos com outros influenciadores para mostrar suas lutas e vulnerabilidades. Portanto, é uma variedade muito grande e um espectro amplo de como é possível manejar essa noção de dificuldade e batalhas afim de trazer as pessoas de volta à base de seguidores e construir essa sensação de autenticidade e conexão. Ainda que se trate de um influenciador de sucesso que, ao mesmo tempo em que se afasta de sua audiência, aproxima-se das marcas e do mainstream das celebridades tradicionais.

Revista Intercom - Há um outro lado dessa estratégia. Influenciadores que produzem um tipo de conteúdo que não está baseado em identificação, mas em projeção e consumo aspiracional. Nesse grupo estariam as blogueiras de moda de luxo ou mesmo as celebridades tradicionais que usam as redes sociais para compartilhar partes de sua vida privada. A pandemia de Covid-19, no entanto, colocou uma questão em circulação: aqueles que pareciam fazer parte das rotinas de suas audiências e geravam conexão por proximidade, mostram-se muito distantes e mesmo em outras realidades. Como resultado, a mídia e os seguidores passaram a questionar se esse tipo de influência ainda faria sentido em um cenário pós-pandemia. Como você vê esse movimento de reivindicação por um tipo de influenciador mais real e uma influência mais positiva? Abidin - Os influenciadores digitais são um produto da cultura popular. Isso significa que também podemos lê-los como um texto cultural popular na medida em que servem a muitos propósitos. Às vezes eles representam a realidade, às vezes eles moldam a realidade, às vezes eles refletem a realidade e há muitos tipos de influenciadores. É difícil dizer qual será o mais popular, qual será o mais receptivo, porque tanto indústria quanto gênero são muito diversificados. Da mesma forma, os públicos também são diversos. Especificamente sobre a pandemia, é possível dizer que as pessoas ao redor do mundo foram afetadas de formas muito diferentes. Eu tenho acompanhado, por exemplo, influenciadoras de moda 
luxuosas que parecem intocadas pela pandemia e, não surpreendentemente, alguns de seus seguidores em posições privilegiadas, em países ricos, também parecem intocados pela pandemia. Portanto, a produção de seu conteúdo permanece. Elas continuam participando de desfiles e eventos virtuais de luxo, continuam consumindo itens de moda exclusivos e nada parou porque, para as audiências e para esses criadores de conteúdo, os negócios seguem normalmente. Para outros influenciadores, os que não estão na mídia tradicional e fazem parte de outras classes sociais, foi necessário exercitar mais o discernimento e usar novas táticas na produção de conteúdo. Isso porque se eles demonstrassem certo grau de irresponsabilidade mantendo suas saídas em feriados, deixando de usar máscaras ou se concentrando apenas no melhor ângulo da refeição do dia, correriam o risco de se afastar de seus seguidores, muitos dos quais estavam enfrentando dificuldades financeiras, emocionais e físicas com a pandemia. Portanto, aqui, independentemente desses influenciadores digitais terem sido afetados pessoalmente pela pandemia, eles precisavam ser mais sensíveis às condições de seus públicos e, portanto, elaborar mensagens mais apropriadas. Existem também os influenciadores minoritários ${ }^{3}$, ou celebridades minoritárias que discuto no artigo Minahs and minority celebrity: parody YouTube influencers and minority politics in Singapore (ABIDIN, 2019). Esses influenciadores, em específico, têm a construção de marca online toda baseada na busca por justiça social, na circulação de diferentes pautas civis e no compartilhamento de pensamentos e vivências de quem, de fato, faz parte de minorias sociais. Portanto, em momentos de crise como a pandemia, esses influenciadores ativam ainda mais suas estratégias de compartilhamento de ideias para promover mensagens sociais e culturais com fins de educação do público. Desse modo, é realmente difícil generalizar, porque influenciador se refere a um tipo de ocupação, um tipo de prática, um modelo de comunicação online. Mas assim como há muitas variedades de seguidores e sujeitos no mundo, há também uma gama variada de influenciadores. Mas o que eu gostaria de salientar sobre a pandemia, com base nos quatro ou cinco artigos que escrevi sobre o tema, é que mais do que nunca os influenciadores são meios de comunicação cruciais. Às vezes, isso pode ser tão sutil quanto influenciadores normalizando o uso de máscaras - ainda que sigam com suas lindas fotos do Instagram ou compartilhem suas lutas nos bastidores. A naturalização de algumas práticas, a partir dos influenciadores digitais, é resultado da quantidade e qualidade das mensagens que eles distribuem. Há, inclusive, influenciadores que estão trabalhando em parceria com marcas, agências de saúde e governos na disseminação de mensagens capazes de educar o público: divulgando a importância da lavagem das mãos, das medidas de distanciamento social, da manutenção de espaços limpos. E, nesses casos, eles estão fazendo aquilo o que fazem de melhor: amplificar algumas mensagens e suprimir outras. É claro que, por outro lado, também temos influenciadores fomentando desinformação sobre saúde,

3 “Celebridade minoritária é a fama e o reconhecimento fundados na mercantilização e representação de um grupo demográfico da sociedade geralmente marginalizado e estigmatizado. Trata-se da validação e celebração de valores minoritários, com uma agenda política que visa a divulgação e crítica aos desafios sistêmicos e pessoais vividos pela minoria social em questão em seu cotidiano. Este conceito segue o marco do trabalho de Deleuze et al. (1983) sobre 'literatura menor’” (ABIDIN, 2019, p. 3 - Tradução nossa). 
o que não é uma novidade da pandemia em si. Antes mesmo, já existiam influenciadores do movimento antivacina, que acreditam na teoria da Terra plana, creem na existência dos Illuminatis e todos os tipos de teorias da conspiração, em suas próprias subculturas. Esses influenciadores também amplificam essas mensagens anticientíficas e suprimem a ciência por trás de todas essas conspirações. Portanto, isso vale para os dois lados. O que é importante, agora, é trabalhar com os influenciadores que podem providenciar os melhores conteúdos de saúde para os seus seguidores. Por fim, é claro que sempre haverá demanda por conteúdo aspiracional ou por influenciadores digitais para entreter, mesmo durante uma pandemia. Mas também há uma busca por influenciadores para prevenir e educar por meio da mediação de informações. Então, ainda há um sentimento de esperança no panorama da comunicação digital.

Revista Intercom - Você mencionou a noção de celebridades minoritárias. No Brasil, nós temos muitos influenciadores digitais envolvidos em discussões sociais que vão desde o racismo e causas indígenas, até gordofobia e padrões estéticos femininos. No entanto, diferente do que você aponta em sua pesquisa, nem todos eles usam o humor como recurso, mesmo assim, a agenda política é evidente. Quais são as principais estratégias usadas por esses influenciadores de acordo com a noção de minority celebrities?

Abidin - Como você disse, o humor e a paródia podem ser usados por esses influenciadores digitais, mas se trata de mais um gênero. No fim, a forma como se transmite a mensagem pode variar, mas a prática e o mecanismo de compartilhamento dessas mensagens são praticamente os mesmos. Eles têm que se concentrar em codificar, decodificar e incorporar mensagens; brincar com sutilezas e subtextos. Os jovens costumam chamar essa prática de shade, quando se fala de algo de forma indireta. Também é necessário dominar diferentes códigos e trabalhar com eles. Isso porque muitos influenciadores minoritários produzem mensagens políticas revestidas de humor para que possam ser protegidos de acusações. Toda vez que forem questionados, podem simplesmente alegar que estavam fazendo "apenas humor, apenas uma paródia!”. Portanto, este espaço ambíguo e liminar é também um ícone clássico dos influenciadores minoritários. Seria possível dizer que, para grande parte dos influenciadores minoritários, uma das principais razões de seu sucesso é a capacidade de falar com públicos muito diferentes ao mesmo tempo. Para aqueles públicos que não dominam questões políticas, por exemplo, o conteúdo de um influenciador minoritário pode ser consumido apenas como um entretenimento humorístico. Já aqueles que estão mais cientes de determinado contexto nacional podem ser capazes de ler as críticas dos influenciadores e reconhecer qual lado do espectro político ele está endossando. E, claro, para os próprios membros de minorias sociais - que são profundamente afetados por essas questões políticas sobre as quais os influenciadores estão falando -, isso pode servir como uma possibilidade de união, apoio e educação mútua. E, até mesmo, como recurso para conversar com seus colegas, para usar como conteúdo educacional mais acessível e para tornar um tópico que geralmente é muito difícil de ser abordado em algo mais fácil com o auxílio da cultura pop. 
O canal MunahHirziOfficial (MHO), que analisei, ilustra esse conceito ${ }^{4}$. Mesmo seguidores de países vizinhos a Singapura ou de outras partes do mundo, que não tinham ideia da política local, ainda eram capazes de vislumbrar uma mensagem de entretenimento ali e passá-la adiante. E por onde quer que essa mensagem circulasse, ela sempre teria o potencial de ser decodificada como uma mensagem política. Em essência, os vídeos desse canal do YouTube continuam a falar para um público muito grande, amplo e diverso, mesmo que nem todos os membros do público sejam capazes de decodificar as multicamadas das mensagens políticas. Ainda assim, a distribuição contínua da informação aumenta as chances de gerar um tipo de consciência política que pode se espalhar para diferentes destinos na internet que é o que esses sujeitos almejam, como bons influenciadores minoritários.

\section{Revista Intercom - Alguns influenciadores digitais reivindicam o uso do termo criador} de conteúdo ou creator. Outros, tentam se afastar da noção de celebridades. Já as blogueiras de moda, precursoras desta prática no Brasil, foram por anos associadas a formadoras de opinião. E, no meio de todos esses atores midiáticos, estão os sujeitos comuns que usam as redes sociais para falar de hobbies ou de sua própria profissão, sem a intenção de se tornarem influenciadores digitais, mas constantemente intitulados “blogueirinhas”. Ainda é possível distinguir essas possibilidades de usos do digital?

Abidin - Acredito que há dois pontos nessa questão: o primeiro se refere ao mainstream das práticas dos influenciadores digitais e o segundo se refere às políticas de nomeações: "Sou um influenciador? Sou um criador de conteúdo? Sou uma celebridade?”. No primeiro ponto, precisamos voltar à definição de uma celebridade da internet, que se refere a uma prática midiática, uma personalidade midiática, um artefato midiático com grande visibilidade. Tendo isso em mente, todo mundo que usa as mídias sociais está se envolvendo em práticas de influência, em certa medida. E mesmo em práticas de celebridades da internet. Em minhas palestras, sempre pergunto aos meus alunos quantos deles têm um perfil no LinkedIn, quantos já pesquisaram seus nomes no Google para imaginar o que um possível empregador poderia ver deles online. Tudo isso é gestão de impressão em espaços digitais. Modulamos a maneira como nos apresentamos, com base em um público imaginado, com o objetivo de garantir que essas pessoas recebam uma fatia positiva de nossa personalidade. Ou seja, queremos esconder as coisas ruins e mostrar apenas as boas. E essas também são práticas dos influenciadores digitais que se constituem como celebridades da internet. Portanto, hoje, todo mundo tem potencial para ser um influenciador, todo mundo está se engajando em algum tipo de prática de celebridade na internet, mas apenas alguns têm as condições de se tornarem um influenciador digital de carreira. Antes, claro, é preciso dizer que, quando falo em "todo mundo", me refiro aos sujeitos que estão online e usando as redes

4 Abidin se refere ao já mencionado artigo Minahs and minority celebrity: parody YouTube influencers and minority politics in Singapore (ABIDIN, 2019) em que define a noção de celebridades minoritárias a partir do canal MunahHirziOfficial do YouTube. Trata-se de um canal que produz paródias a partir de grandes sucessos da música pop mundial. Os youtubers em questão representam uma minoria social conhecida como minah, subcultura malaia. 
sociais digitais. Isto posto, seu comentário sobre pessoas sendo chamadas pejorativamente de "blogueirinhas" revela o emprego de um apelido que identifica as práticas que eles estão emulando - as culturas de influenciadores e blogueiras. No entanto, o diminutivo no apelido é uma avaliação de seu sucesso; apesar de todas as camadas desse tipo de atividade, esses sujeitos ainda não têm certo nível de celebritização. Aqui, retomamos o início de nossa conversa: as possibilidades de se encarar os influenciadores digitais a partir da perspectiva do trabalho digital versus a perspectiva da celebridade e dos públicos. O termo "blogueirinha” também tende a implicar que, para ser um influenciador de sucesso, você precisa de habilidades ou dinheiro, formas de monetização atreladas a isso. Quando, na verdade, muitos influenciadores em grupos minoritários ou subculturas não têm na influência digital uma carreira, mas, ainda assim, atendem a todas as outras práticas: têm a capacidade de persuadir seus públicos, produzem conteúdo a partir de recortes de suas vidas, amplificam e suprimem mensagens. Pode ser, no entanto, que eles não faturem financeiramente com isso. O que, de certo modo, é aceitável, já que há também outros valores derivados dessa atividade, como a capacidade de pautar algumas conversas e influenciar na mudança de opinião das pessoas que os acompanham. Assim, chamar alguém de "blogueirinha” revela uma visão estereotipada de que aquela pessoa está em busca de uma carreira como influenciador digital. Quando, na verdade, o que se está buscando, de fato, é influenciar um pequeno grupo cultural ou um pequeno grupo social o que, de novo, é perfeitamente aceitável. Muitos influenciadores minoritários têm sucesso apenas dentro de um grupo social e cultural específico e podem ter grande valor e poder de persuasão. Por outro lado, alguns grandes influenciadores se tornaram tão distantes e alienados de seu público que, ainda que detenham números milionários de seguidores em suas redes sociais, nem todos os seus públicos serão impactados por suas mensagens ou acreditarão em seu conteúdo. Muitos seguidores, inclusive, podem estar ali apenas como observadores passivos e inativos. Portanto, isso é algo para se ter em mente quando avaliamos o fenômeno das “blogueirinhas”. Por sinal, também existe um vocabulário semelhante para isso em toda a Ásia, o que me permite fazer esse tipo de avaliação do fenômeno no Brasil. O segundo ponto da pergunta passa pelas políticas de nomeação e traz outros fatores para a análise. Aqui, devemos olhar para historicidade, cultura de plataforma, gênero e comercialidade. A começar pela historicidade, é preciso reconhecer que esse ponto é muito específico para diferentes partes do mundo. Em algumas partes do Sudeste Asiático, as primeiras plataformas a permitirem o surgimento de influenciadores digitais foram as plataformas de blog como LiveChannel, OpenDiary, Blogger e, muito mais tarde, o Wordpress. Então, nessa fase, a primeira geração de influenciadores costumava ser chamada de blogueiros ${ }^{5}$. E mesmo mais adiante, em um momento mais profissionalizado do mercado e ocupando plataformas como YouTube e Instagram, ainda havia certo prestígio nesse título, já que sinalizava um legado, uma referência a sua história de origem e seu lugar na linha do tempo do surgimento dos

5 Discussão semelhante, a partir dos influenciadores digitais brasileiros, é empreendida no trabalho "Influenciadores digitais: conceitos e práticas em discussão” (KARHAWI, 2017a). 
influenciadores digitais. Os públicos, portanto, parecem reconhecer a existência de certo prestígio associado a esse termo. Em segundo lugar, precisamos pensar nas culturas de plataforma. Quando o Instagram viveu seu grande boom, entre 2013 e 2015, muitas pessoas começaram a se referir a si mesmas como instagrammers. Esse foi um ponto de virada, uma vez que o conteúdo imagético, pictórico, se tornou popular. A cultura do Instagram não exigia uma habilidade de escrever frases memoráveis, conectar fatos e dados ou ter boas habilidades de escrita como um blogueiro. Se você pudesse tirar uma boa foto, já seria o suficiente para se tornar um influenciador do Instagram e nomear-se como instagrammer. Portanto, as lógicas de nomeação revelam diferentes tipos de influenciadores e conjuntos de habilidades específicos de acordo com a plataforma em que cada um surgiu. E embora cada plataforma tenha regras e parâmetros específicos acerca do que seria um influenciador de sucesso, as empresas de tecnologia também tentam marcar os influenciadores que nasceram primeiro em suas plataformas. Basta olharmos para os tiktokers ou youtubers. Inclusive, o termo youtuber acaba funcionando como um nome genérico para quem faz vídeos, quase um sinônimo para videoblogger, mesmo quando estes atuam em outras plataformas. Isso acontece com os produtores da AfreecaTV, por exemplo, uma plataforma importante na Ásia. Por outro lado, o YouTube realiza eventos como a FanFest ${ }^{6}$ e até treina parceiros do YouTube, o que resulta na inserção de uma marca corporativa em toda uma classe de influenciadores digitais que cresceu organicamente nessa plataforma. Hoje, é possível testemunhar exatamente o mesmo movimento acontecendo no TikTok. Antes, costumávamos nos concentrar nos musers, influenciadores do Musically, ou nos viners do Vine. Portanto, há uma linguagem corporativa e um estilo de desempenho específico da plataforma vinculados ao vocabulário usado para referirmos aos influenciadores digitais. O terceiro ponto é reconhecer o gênero como parte importante de como muitos influenciadores se identificam. A cobertura da mídia tradicional sobre essa indústria, por exemplo, tende a se concentrar nos segmentos de moda, beleza, cuidados com a pele e, portanto, em um gênero feminizado. E com o tempo, começamos a pensar nos influenciadores como uma indústria feminina. Tanto que esquecemos que os jogadores de e-sports no YouTube são quase todos homens, o mesmo na Twitch. Mas, para eles, a política de nomeação foi pré-estabelecida por uma definição de gênero com consequências na percepção de quem são os influenciadores digitais. É por isso que é comum vermos o uso de nomeações como streamer, gamers, youtubers como uma forma de se desassociar, se afastar dessa cultura de influenciadores. Tudo isso revela políticas de nomeação. Por último, é preciso tratar da comercialidade, que tem relação direta com o "momento de vida" em que o influenciador se encontra. Por exemplo, se esse deseja começar uma carreira e se beneficiar da popularidade de uma plataforma, pode ser que opte por produzir conteúdo no TikTok e se intitule tiktoker. Mas se quiser investir em uma carreira polivalente - o que é considerado importante para os clientes que buscam pluralidade de plataformas, diferentes tipos de conteúdos e de audiências

6 Evento realizado pela plataforma em diferentes cidades ao redor do mundo. Nele, os fãs e os criadores de conteúdo do YouTube se reúnem para assistir palestras, shows e se conhecerem. 
-, pode se considerar um influenciador, dando essa impressão de abrangência. No entanto, há influenciadores que se destacam a partir de títulos que conferem certo distanciamento do grupo de influenciadores digitais mais dominante. São os casos em que a nomeação passa por termos como CEOs, fotógrafos digitais, empreendedores, blogueiros de moda. Trata-se de uma tentativa de separação de todo um grupo de influenciadores ou, em alguns casos, a evidência de outras habilidades mais específicas como a dos fotógrafos. Mas, de certa forma, também está em jogo a comercialidade uma vez que é possível apelar para fins comerciais específicos de cada segmento. Na indústria da moda, se autodenominar um influenciador digital, em geral, pode colocar esse sujeito na base de uma escada social do campo. Mas ao se tratar de um fotógrafo ou modelo - ainda que com uma carreira iniciada no Instagram, em um blog -, isso tende a conferir mais credibilidade e mobilidade na indústria da moda. A última parte da comercialidade tem a ver com o patamar que os influenciadores digitais têm alcançado. É comum encontrar influenciadores extremamente bem-sucedidos que passaram a investir em suas próprias empresas criativas, criar redes de canais, abrir agências de assessoria de carreira para outros influenciadores, formar equipes completas de profissionais que lidam internamente com fechamento de contratos e negociações comerciais. Esse cenário é muito distinto daquele de quatro ou cinco anos atrás, em que o símbolo de sucesso entre os influenciadores era ser contratado por um canal de televisão ou integrar o casting de uma agência de influenciadores digitais. Evidencia-se, portanto, o momento de vida desses sujeitos. Atualmente, os influenciadores de maior sucesso que iniciam suas próprias empresas ou fundam startups passam a ser CEOs e, em certa medida, diversificam o rótulo de influenciador digital ao pleitear títulos como os de criadores de conteúdo, criativos digitais ou mesmo o de especialistas em marketing digital. Rótulos mais amplos como esses permitem que os influenciadores digitais transitem mais facilmente no mercado e disputem espaços midiáticos, anunciantes, clientes com grandes corporações, já que elas passam a ser suas principais concorrentes. Assim, as mudanças nos títulos - de influenciador a criador digital, de youtuber a produtor de conteúdo, de instagrammer a agente digital - têm relação direta com certo nível de compreensão das lógicas de mercado e de negócios. Resultado de um processo de profissionalização e sagacidade comercial oriundos de anos de atuação nessa indústria.

\section{Referências}

ABIDIN, C. \#familygoals: Family Influencers, Calibrated Amateurism, and Justifying Young Digital Labor. Social Media + Society. Volume: 3 issue: 2, 2017.

ABIDIN, C. Communicative Intimacies: Influencers and Perceived Interconnectedness. Journal of Gender, New Media, \& Technology, College Park, v. 8, nov. 2015. Disponível em: http://adanewmedia.org/2015/11/ issue8-abidin/. Acesso em: 12 dez. 2017.

ABIDIN, C. Internet Celebrity: Understanding Fame Online. Bingley, UK: Emerald Publishing, 2018. 
ABIDIN, C. Minahs and minority celebrity: parody YouTube influencers and minority politics in Singapore. Celebrity Studies, 2019. DOI: 10.1080/19392397.2019.1698816.

ABIDIN, C.; BROWN, M. L. Microcelebrity Around the Globe: Approaches to cultures of internet fame. Bingley, UK: Emerald Publishing, 2018.

HORTON, D.; WOHL, R. Mass Communication and Para-Social Interaction, Psychiatry, 1956. DOI: 10.1080/00332747.1956.11023049.

KARHAWI, I. Influenciadores digitais: conceitos e práticas em discussão. Communicare, São Paulo, v. 17, edição comemorativa, p. 46-61, 2017a.

KARHAWI, I. Na tela da TV e do computador: as celebridades youtubers. In: SAAD-CORRÊA, E. N.; SILVEIRA, S. C. Tendências em Comunicação Digital 2. São Paulo: ECA-USP, 2017b.

LEAVER, T.; HIGHFIELD, T.; ABIDIN, C. Instagram: Visual Social Media Cultures. Cambridge: Polity Press, 2020.

SILVA, M. E. de O. S.; ANJOS, M. F. DOS. Relacionalidade como condição necessária da identidade humana: perspectiva crítica de bioética. Revista Brasileira de Bioética, v. 14, p. 151, 12 abr. 2019.

\section{Issaaf Karhawi}

Doutora em Ciências da Comunicação pela Escola de Comunicações e Artes da Universidade de São Paulo (ECA-USP) e mestre pela mesma instituição. Graduou-se em jornalismo pela Universidade Federal de Mato Grosso (UFMT). Atua no grupo de pesquisa em comunicação digital, COM+ (ECAUSP). É autora do livro "De blogueira a influenciadora: etapas de profissionalização da blogosfera de moda brasileira”, publicado pela Editora Sulina, na coleção Cibercultura (2020). Atualmente, também é docente no curso de pós-graduação em Mídia, Informação e Cultura do Centro de Estudos Latino-Americanos sobre Cultura e Comunicação (CELACC-USP).E-mail: issaaf@gmail.com.

Recebido em: 26.10.2020

Aprovado em: 05.02.2021

Este artigo é publicado em acesso aberto (Open Access) sob a licença Creative Commons Attribution Non-Commercial (CC-BY-NC), que permite uso, distribuição e reprodução em qualquer meio, sem restrições, desde que sem fins comerciais e que o trabalho original seja corretamente citado.

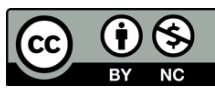

